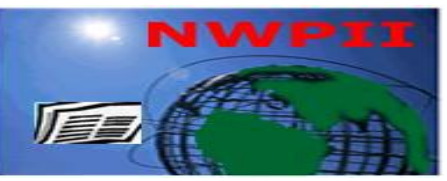

American Journal of

Biomedical Sciences

ISSN: 1937-9080

nwpii.com/ajbms

\title{
Effect of Exercise Training and Adropin Treatment on Thyroid and Testicular Function Changes in Obese Type 2 Diabetic Rats
}

\author{
Khaled Abdelfattah Abulfadle ${ }^{1 *}$, Naglaa Atef Ahmed ${ }^{1}$ \\ ${ }^{1}$ Department of Physiology, Faculty of Medicine, Zagazig University, Zagazig, Egypt. \\ *Corresponding Author \\ Dr. Khaled Abdelfattah Abulfadle \\ Physiology Department, Faculty of Medicine \\ Zagazig University \\ Egypt \\ Email: khafadle@gmail.com
}

Received:03 June 2019; | Revised:25 June 2019; | Accepted:06 December 2019

\begin{abstract}
Background: Type 2 diabetes mellitus (T2DM) and thyroid dysfunctions are commonly observed concomitant endocrinopathies that have a common pathogenesis of insulin resistance. Also, adropin is a metabolic hormone that is secreted by many structures in the body. On the other hand, moderate exercise training was recorded to combat changes that occurred with obesity. But, the available information about the effect of type 2 diabetes mellitus on testicular function was contradictory and a scarce data was available on the effect of exercise training and adropin treatment on both thyroid and testicular functions in obese type 2 diabetic rats.
\end{abstract}

Aim: This study investigated thyroid and testicular function changes occurred in obese type 2 diabetic rats and explored the effect of moderate exercise training and adropin treatment.

Materials and Methods: Rats in this 10 weeks' study were divided randomly into two main groups, lean non-diabetic (were fed on ordinary chow) and obese diabetic [were fed on high fat and received streptozotocin $(35 \mathrm{mg} / \mathrm{kg})$ at the start of the 5th week]. Each main group was subdivided into sedentary, exercised and adropin treated subgroups. For the last 5 weeks of the study, rats in the exercised subgroups were exposed to a moderate swimming exercise protocol, while those in the adropin treated subgroups were administered adropin daily $(2.1 \mu \mathrm{g} / \mathrm{kg})$.

Results: Obese diabetic groups had a significant increase in the final body weight, weight difference, body mass index (BMI), serum levels of [glucose, insulin, triglycerides (TG), total cholesterol (TC), low density lipoprotein (LDL), tumor necrosis factor alpha (TNF $\alpha$ ), malondialdehyde (MDA) and thyroid stimulating hormone (TSH)] and value of homeostasis model assessment of insulin resistance index (HOMA-IR), with a significant decrease in serum [adropin, high-density lipoprotein (HDL), superoxide dismutase (SOD), thyroxine (T4), triiodothyronine (T3), follicle stimulating hormone (FSH), luteinizing hormone (LH) and testosterone] and epididymal sperm [count, motility and deformity] in comparison with the lean non-diabetic groups. Also, within the obese diabetic groups, serum adropin was negatively associated with weight difference, BMI, serum (glucose, TC, TNF $\alpha$ and TSH) and HOMA-IR, but it was 
positively correlated to serum (HDL, SOD, T4, LH and testosterone) and epididymal sperm count. With both moderated exercise training (obese diabetic exercised group) and adropin treatment (obese diabetic adropin treated group), a significant decrease was detected in the final body weight, weight difference, BMI, serum levels of (glucose, insulin, TG, TC, LDL, TNF $\alpha$, MDA and TSH) and HOMA-IR value, with a significant elevation in serum (adropin, HDL, SOD, T4, T3, FSH, LH and testosterone) and epididymal sperm [count, motility and deformity] in comparison with the obese diabetic sedentary group.

Conclusion: Both moderate exercise training and exogenous adropin treatment deteriorated thyroid and testicular function changes occurred in obese type 2 diabetic rats through their anti-inflammatory and antioxidant effects.

Keywords: Adropin, Exercise training, Thyroid function, Testicular function

\section{Introduction}

Adropin is a metabolic hormone that was isolated in 2008 by Kumar et al and is expressed by the energy homeostasis associated (Enho) gene in the liver and the brain of mice [1]. Also, it is expressed in the rat brain, endothelium, liver, skeletal muscle and pancreas ${ }^{[2,3]}$. S Gao, et al. ${ }^{[4]}$ declared that treatment of diet-induced obese (DIO) mice with adropin (34 - 76) improved glucose tolerance, oxidative glucose metabolism and insulin receptor signaling in skeletal muscle. Also, $\mathrm{R}$ Akcilar, et al. ${ }^{[5]}$ noticed that adropin regulated glucose and lipid metabolism in rats.

$\mathrm{KG}$ Kumar, et al. ${ }^{[1]}$ found that liver Enho expression was suppressed in DIO mice and they have indicated an association between adropin deficiency, increased adiposity, and insulin resistance. Also, K Ganesh - Kumar, et al. [6] detected insulin resistance in the adropin knockout mice. Obesity which is a common health problem refers to excessive accumulation of body fat, and has a negative impact on health and is linked to many diseases including type 2 diabetes mellitus (T2DM) ${ }^{[7]}$.

On the other hand, the effect of obesity on fertility has been extensively investigated. However, the results of those studies showed controversies. A meta-analysis performed by MacDonald et al. found no statistically significant association between body mass index (BMI) and semen parameters ${ }^{[8]}$. Also, AS Aggerholm, et al. [9] and C Niederberger [10] claimed no relationship between obesity and sperm concentration, motility or morphology. On the other hand, C-W Tsao, et al. ${ }^{[11]}$ found a significant Jshaped association between BMI and an abnormal sperm count.
Also, JE Chavarro, et al. ${ }^{[12]}$, F Hammiche, et al. ${ }^{[13]}$ and N Sermondade, et al. ${ }^{[14]}$ reported that increased BMI was accompanied by poor semen quality, decreased sperm concentration, decreased normal motile sperm cells, and increased DNA fragmentation index. ES Ford, et al. ${ }^{[15]}$ stated that when obesity was accompanied with a sedentary lifestyle, it may predispose to T2DM. C Han, et al. ${ }^{[16]}$ observed that the T2DM was linked with a 1.93fold increase in risk of hypothyroidism. Less data was available about the relation between adropin and thyroid function, although, G Akbaba, et al. [17] found that adropin levels were lower in hypothyroidism than those in the control group.

On the other hand, MR Nikoobakht, et al. ${ }^{[18]}$ reported that hypothyroidism adversely affected sperm count, morphology, and motility. CK Roberts, et al. ${ }^{[19]}$ and I Moinuddin and DJ Leehey ${ }^{[20]}$ stated that exercise training was a measure to combat obesity and its complications. Also, $\mathrm{H}$ Zhang, et al. ${ }^{[21]}$ reported that exercise improved serum adropin levels in obese patients. Moreover, E Rahimi, et al. [22] found that exercise training affected thyroid function.

Thus, this study aimed to investigate the effect of exercise training and adropin treatment on testicular and thyroid function changes in obese type 2 diabetic rats and to clarify the possible involved mechanisms.

\section{Materials and Methods}

Animals: 48 adult male albino rats of local strains weighing $180-210$ gm, obtained from Zagazig Faculty of Veterinary Medicine, housed in a light- and temperature-controlled room on a12 
$\mathrm{h} / 12 \mathrm{~h}$ light - dark cycle and had free access to food and water throughout the experimental period.

The experimental procedures were achieved according to the guide for the care and use of laboratory animals (8th edition, National Academic press) which was approved by Zagazig University Institutional Animal Care and Use Committee (ZUIACUC); Zagazig, Egypt.

Drugs and chemicals: Rats (in obese diabetic group) received a single intraperitoneal (i.p.) injection of streptozotocin (STZ, $35 \mathrm{mg} / \mathrm{kg}$, SigmaAldrich, St. Louis, MO, USA) dissolved in $0.1 \mathrm{M}$ citrate buffer with $\mathrm{pH}$ of $4.5^{[23]}$. Rats of adropin treated groups received a single daily i.p. dose of adropin (34-76) (2.1 $\mu \quad \mathrm{g} / \mathrm{kg}, \quad$ Phoenix Pharmaceuticals, Inc., Burlingame, USA) dissolved in saline ${ }^{[5]}$.

Experimental design (table 1): After one week of acclimatization, rats were divided randomly into two groups, I (lean non-diabetic) and II (obese diabetic). Group I (lean non-diabetic group, $n=24$ ): the animals in this group were fed on ordinary laboratory chow diet, consisted of carbohydrate $62.8 \%$, protein $25.8 \%$ and fat $11.4 \%$ (obtained from Zagazig Faculty of Agriculture), for 10 weeks (duration of the study), and further subdivided into 3 subgroups; group IA (sedentary group, $n=8$ ) in which the rats remained sedentary in their cages (no exercise), group IB (exercised group, $n=8$ ) in which the rats were trained by swimming exercise training of moderate intensity (one hour/day, five days/week) ${ }^{[24]}$ in the last 5 weeks of this 10-week-study, and, group IC (adropin treated group, $n=8$ ) in which rats received a single daily intraperitoneal (i.p.) dose of adropin (34-76) dissolved in saline at a dosage of $2.1 \mu \mathrm{g} / \mathrm{kg} / \mathrm{day}{ }^{[5]}$ for the last 5 weeks of the study while they remained sedentary in their cages. Rats of lean non-diabetic sedentary and lean non-diabetic exercised groups were injected i.p. daily with a single dose of $0.1 \mathrm{ml}$ normal saline in the last 5 weeks of the study.

Group II [obese diabetic, $\mathrm{n}=24$ ]: rats in this group were fed a highly palatable specially formulated high fat diet (HFD), to induce obesity, consisted of $33 \%$ standard rat chow, $33 \%$ Nestle $\AA$ condensed milk, $7 \%$ sucrose, and $27 \%$ water ${ }^{[25]}$, for ten weeks (duration of the study). At the start of the 5th week of the study, rats were kept in an overnight fast and injected with a single dose of STZ $35 \mathrm{mg} / \mathrm{kg}$ body weight in $0.1 \mathrm{M}$ citrate buffer pH 4.5, i.p. ${ }^{[23]}$. One week after the STZ injection, the non-fasting blood glucose levels of all animals were measured in the blood collected from the tail vein by using a portable glucometer (Bionime GM300, Taiwan). The animals with blood glucose levels higher than $300 \mathrm{mg} / \mathrm{dL}$ were accepted for inclusion as diabetic ${ }^{[5]}$.

Obese diabetic rats of group II were further subdivided into 3 subgroups; group IIA (obese diabetic sedentary, $n=8$ ) in which the rats remained sedentary in their cages (no exercise), group IIB (obese diabetic exercised, $n=8$ ) in which the rats were trained by swimming exercise training of moderate intensity in the last 5 weeks of the study as in group IB, and, group IIC (obese diabetic adropin treated, $\mathrm{n}=8$ ) in which the rats received a single daily i.p. dose of adropin (34-76), as in group IC, for the last 5 weeks of the study while they remained sedentary in their cages.

Rats of obese diabetic sedentary and obese diabetic exercised groups were injected i.p. daily with a single dose of $0.1 \mathrm{ml}$ normal saline in the last 5 weeks of the study. Also, rats of group I received a single i.p. injection with $0.1 \mathrm{ml}$ normal saline at the start of the 5th week of the study.

Table 1: Experimental design

\begin{tabular}{|l|c|c|c|c|c|c|}
\hline & \multicolumn{3}{|c|}{ Group I (Lean Non-diabetic) } & \multicolumn{3}{c|}{ Group II (Obese Diabetic) } \\
\cline { 2 - 7 } & $\begin{array}{c}\text { Sedentary } \\
\text { (IA) }\end{array}$ & $\begin{array}{c}\text { Exercised } \\
\text { (IB) }\end{array}$ & $\begin{array}{c}\text { Adropin } \\
\text { treated (IC) }\end{array}$ & $\begin{array}{c}\text { Sedentary } \\
\text { (IIA) }\end{array}$ & $\begin{array}{c}\text { Exercised } \\
\text { (IIB) }\end{array}$ & $\begin{array}{c}\text { Adropin treated } \\
\text { (IIC) }\end{array}$ \\
\hline Number of rats & 8 & 8 & 8 & 8 & 8 & 8 \\
\hline Study duration & 10 weeks & 10 weeks & 10 weeks & 10 weeks & 10 weeks & 10 weeks \\
\hline Ordinary diet & $\checkmark$ & $\checkmark$ & $\checkmark$ & & & \\
\hline HFD & & & & $\checkmark$ & $\checkmark$ & $\checkmark$ \\
\hline Streptozotocin i.p. & & & & $\checkmark$ & $\checkmark$ & $\checkmark$ \\
\hline Exercised & & $\checkmark$ & & & $\checkmark$ & \\
\hline Adropin (34-76) i.p. & & & $\checkmark$ & & & $\checkmark$ \\
\hline
\end{tabular}

HFD: High fat diet, i.p.: intraperitoneal injection. 
Body mass index (BMI) assessment: BMI was evaluated at the end of the 4th week to confirm occurrence of obesity (more than $0.68 \mathrm{gm} / \mathrm{cm}^{2}$ ), and, at the end of the study to explore the changes in BMI among different groups. This was achieved by using the equation: $\mathrm{BMI}=[$ Body weight $(\mathrm{gm})]$ / [Length ${ }^{2}\left(\mathrm{~cm}^{2}\right)$ (from nose to anus length)] ${ }^{[26]}$. Rats in HFD fed groups that did not gain weight after 4 weeks of the start of HFD were considered resistant and were excluded.

Swimming exercise program: The rats in exercised groups practiced a moderate intensity swimming exercise in a cylindrical tank $80 \mathrm{~cm}$ high, $45 \mathrm{~cm}$ diameter, and filled with $32-35^{\circ} \mathrm{C}$ water 45 $\mathrm{cm}$ deep, one hour/day, five days/week for 5 weeks [27]. For 15 minutes/day, swimming rats were initially trained and the duration was increased gradually such that the rats were able to perform exercise for one hour/day, that was achieved in one week [28]. Exercise was practiced between 9.30$10.30 \mathrm{am}$. At end of each session of exercise, rats were kept to dry in a warm environment ${ }^{[29]}$.

Assessment of serum glucose, insulin, lipid profile, hormones, inflammation and oxidative stress: At the end of the experimental period and after 12 hours fasting, rats were sacrificed by decapitation, blood samples were collected and allowed to clot at room temperature $\left(23 \pm 3^{\circ} \mathrm{C}\right)$ before centrifuging at 3000 revolutions per minute (rpm) for 15 minutes. In dark containers, the separated serum was stored at $-20^{\circ} \mathrm{C}$ for biochemical assay using suitable kits and following manufacture instructions. Serum levels of glucose, insulin, total cholesterol (TC), triglycerides (TG), high-density lipoprotein (HDL) and tumor necrosis factor alpha $(\mathrm{TNF} \alpha)$ were estimated using specific kits (Sigma-Aldrich, St. Louis, MO, USA). Also, enzyme-linked immunosorbent assay (ELISA) kits (LifeSpan BioSciences, Washington, USA) were used for estimating serum levels of adropin, testosterone, follicle stimulating hormone (FSH), luteinizing hormone (LH), triiodothyronine (T3), thyroxine (T4) and thyroid stimulating hormone (TSH). Furthermore, serum superoxide dismutase (SOD) and malondialdehyde (MDA) levels were assessed spectrophotometrically using commercial kits (Biodiagnostics, Egypt). Absorbance was evaluated using an UV-visible spectrophotometer (UV - 1601PC; Shimadzu, Japan).

Serum levels of low-density lipoprotein (LDL) were investigated using Friedewald formula:

$\operatorname{LDL}(\mathrm{mg} / \mathrm{dl})=[\mathrm{TC}]-[(\mathrm{HDL})+(\mathrm{TG} / 5)]^{[30]}$

Assessment of insulin resistance: Homeostasis model assessment of insulin resistance (HOMA-IR) index was measured by the formula:

HOMA-IR $=[($ Insulin in $\mu \mathrm{IU} / \mathrm{L}) \mathrm{X}$ (Glucose in $\mathrm{mg} / \mathrm{dl})] / 405^{[31]}$.

Assessment of epididymal sperm count, motility and morphology: The separated epididymis was minced and placed in $1 \mathrm{ml}$ of phosphate buffered saline ( $\mathrm{pH}$ 7.2) to have a suspension [32] used to assess the sperm count by the standard method in Neubauer's chamber ${ }^{[33]}$. In leukocyte hemocytometer, a part from the suspension (up to 0.5 ) was taken and diluted with phosphate buffered saline up to the mark 11. After mixing the suspension well, it was applied into Neubauer's counting chamber. The total sperm count in 8 squares except the central erythrocyte area of 1 $\mathrm{mm} 2$ each was determined under light microscope at $400 \mathrm{X}$, and multiplied by $5 \times 104$ to calculate the number of spermatozoa $/ \mathrm{ml}$. The percentage of sperm motility was calculated by dividing the number of motile sperm cells by the total number of sperm cells (motile and non-motile), where the motile sperm cells were those that displayed some movement, while the non-motile sperm cells were those which were not moving [34]. Also, the deformed sperm percentage was calculated.

Statistical Analysis: The obtained data was expressed as mean \pm standard deviation (SD). For statistical significance, one-way ANOVA and Tukey HSD for Post hoc multiple comparisons were used to compare means. The software, IBM Statistical Package for Social Sciences (SPSS) Version 25 Software for Windows, was used for that purpose. Also, Graph Pad Prism (Version 8 Software for Windows) was used to analyze the Pearson's correlation coefficient between serum levels of adropin and different studied parameters within the obese diabetic groups (sedentary, exercised and adropin treated). Significance was considered with $\mathrm{p}$ value $\leqslant 0.05$. 


\section{Results}

In this study, HFD and a single dose of STZ were used for induction of T2DM and then we studied the effects of both moderate swimming exercise training and exogenous adropin treatment on thyroid and testicular function changes in obese diabetic rats in comparison to lean non-diabetic rats.

Effect of exercise training and exogenous adropin treatment on biochemical changes in obese diabetic rats (table 2 and Fig. 1): Our results showed a significant $(\mathrm{P}<0.05)$ increase in final body weight, weight difference (the difference between final and initial body weight), final BMI, serum level of (glucose, insulin, TC, TG, LDL, TNF $\alpha$ and MDA) and HOMA-IR value, but, a significant $(\mathrm{P}<0.05)$ decrease in serum level of adropin, HDL and SOD in obese diabetic sedentary group, in comparison to that of the lean non-diabetic sedentary group. These results confirmed incidence of insulin resistance, disturbance in lipid profile, deficiency of serum adropin, inflammation and oxidative stress in obese diabetic sedentary rats.

On performing exercise training (in obese diabetic exercised group); final body weight, weight difference, final BMI, serum level of (glucose, insulin, TC, TG, LDL, TNF $\alpha$ and MDA) and HOMA-IR value were significantly $(\mathrm{P}<0.05)$ reduced, but, a significant $(\mathrm{P}<0.05)$ elevation was noticed in serum level of adropin, HDL and SOD in comparison to obese diabetic sedentary group. These results reflected that exercise training deteriorated the metabolic, inflammatory and oxidative stress changes occurred in obese diabetic sedentary rats and also increased serum adropin level.

Also, on adropin treatment (in obese diabetic adropin treated group), a significant $(\mathrm{P}<0.05)$ decrease was noticed in final body weight, weight difference, final BMI, serum level of (glucose, insulin, TC, TG, LDL, TNF $\alpha$ and MDA) and HOMA-IR value, but, a significant $(\mathrm{P}<0.05)$ increase was reported in serum level of adropin, HDL and SOD in comparison to those in obese diabetic sedentary group. These results reflected that adropin treatment improved the metabolic, inflammatory and oxidative stress changes occurred in obese diabetic sedentary rats.

Effect of exercise training and exogenous adropin treatment on thyroid function changes in obese diabetic rats (table 3): In obese diabetic sedentary group, a significant $(\mathrm{P}<0.001)$ increase in serum level of TSH was found, but there was a significant $(\mathrm{P}<0.001)$ decrease in serum levels of $\mathrm{T} 3$ and $\mathrm{T} 4$, in comparison to that in the lean nondiabetic sedentary group. These results declared occurrence of hypothyroidism in obese diabetic sedentary rats. On either performing exercise training (in obese diabetic exercised group) or adropin treatment (in obese diabetic adropin treated group), serum TSH levels were significantly $(\mathrm{P}<0.001)$ reduced, but serum levels of $\mathrm{T} 3$ and $\mathrm{T} 4$ were significantly $(\mathrm{P}<0.001)$ elevated in comparison with those in the obese diabetic sedentary group.

Table 2. Biochemical changes among different groups

\begin{tabular}{|c|c|c|c|c|c|c|}
\hline Group & \multicolumn{3}{|c|}{ Group I (Lean Non-diabetic) } & \multicolumn{3}{|c|}{ Group II (Obese Diabetic) } \\
\hline Parameter & $\begin{array}{l}\text { Sedentary } \\
\text { (IA) }\end{array}$ & $\begin{array}{l}\text { Exercised } \\
\text { (IB) }\end{array}$ & $\begin{array}{c}\text { Adropin } \\
\text { treated (IC) }\end{array}$ & $\begin{array}{l}\text { Sedentary } \\
\text { (IIA) }\end{array}$ & $\begin{array}{l}\text { Exercised } \\
\text { (IIB) }\end{array}$ & $\begin{array}{l}\text { Adropin treated } \\
\text { (IIC) }\end{array}$ \\
\hline Initial BW (gm) & $191.8 \pm 10.4$ & $194 \pm 11.4$ & $192.1 \pm 11.5$ & $195 \pm 9.8$ & $194.9 \pm 12.7$ & $194.1 \pm 11.2$ \\
\hline Final BW (gm) & $217.6 \pm 8.3$ & $201.6 \pm 8.6$ & $213 \pm 4.3$ & $399 \pm 25.1^{* \# \$}$ & $348.5 \pm 21.4^{* \# \$}$ & $373.6 \pm 10.9^{* \# \$ \uparrow}$ \\
\hline WD (gm) & $25.9 \pm 12.8$ & $7.6 \pm 6.2$ & $20.9 \pm 8.2$ & $204 \pm 23^{* \# \$}$ & $\begin{array}{c}153.6 \pm 18.3^{* \# \$} \\
\end{array}$ & $179.5 \pm 13.5^{* \# \$ \|_{\dagger}^{\dagger}}$ \\
\hline BMI $\left(\mathrm{gm} / \mathrm{cm}^{2}\right)$ & $0.54 \pm 0.05$ & $0.49 \pm 0.04$ & $0.53 \pm 0.04$ & $0.93 \pm 0.09^{* \# \$}$ & $0.81 \pm 0.04^{* \# \$ \Phi}$ & $0.84 \pm 0.04^{* \# \$ \Phi}$ \\
\hline Serum adropin $(\mathrm{ng} / \mathrm{ml})$ & $36.5 \pm 1.6$ & $36.8 \pm 0.8$ & $38.1 \pm 0.9$ & $23.4 \pm 1.7^{* \# \$}$ & $31.7 \pm 2.1^{* \# \$ \Phi}$ & $37.7 \pm 1.4{ }^{9 \dagger}$ \\
\hline Serum glucose $(\mathrm{mg} / \mathrm{dl})$ & $75.5 \pm 1.3$ & $72 \pm 2$ & $73 \pm 0.4$ & $416.3 \pm 10.7^{* \# \$}$ & $261.2 \pm 4.3^{* \# \$}$ & $284.3 \pm 4.9^{* \# \$ \uparrow \dagger}$ \\
\hline Serum insulin $(\mu \mathrm{IU} / \mathrm{L})$ & $12.4 \pm 1.4$ & $10.2 \pm 0.9$ & $11.4 \pm 1.2$ & $38.6 \pm 1.7^{* \# \$}$ & $28.2 \pm 1.5^{* \# \$ \Phi}$ & $30.8 \pm 2.2^{* \# \$ \uparrow \dagger}$ \\
\hline HOMA-IR & $2.3 \pm 0.3$ & $1.8 \pm 0.2$ & $2.1 \pm 0.2$ & $39.7 \pm 2.1^{* \# \$}$ & $18.2 \pm 1.1^{* \# \$ \Phi}$ & $21.6 \pm 1.5^{* \# \$ \uparrow \dagger}$ \\
\hline Serum TC (mg/dl) & $158.6 \pm 6$ & $157.1 \pm 5.7$ & $159.1 \pm 4.8$ & $287.8 \pm 6.6^{* \# \$}$ & $242.8 \pm 3.8^{* \# \$ \Phi}$ & $260.3 \pm 5.8^{* \# \$ \uparrow \dagger}$ \\
\hline
\end{tabular}




\begin{tabular}{|c|c|c|c|c|c|c|}
\hline Serum TG (mg/dl) & $129.5 \pm 4$ & $121.9 \pm 4.9$ & $125.3 \pm 7$ & $266.4 \pm 16.3^{* \# \$}$ & $197.8 \pm 15^{* \# \$}$ & $207.5 \pm 15.3^{* \# \$ \Phi}$ \\
\hline Serum HDL (mg/dl) & $64.9 \pm 2.4$ & $68.3 \pm 1.7^{*}$ & $65.8 \pm 1.7^{\#}$ & $26.4 \pm 1.4^{* \# \$}$ & $52.8 \pm 2.4^{* \# \$}$ & $46.3 \pm 1.7^{* \# \$ \uparrow}$ \\
\hline Serum LDL (mg/dl) & $67.9 \pm 5.7$ & $64.4 \pm 6.1$ & $68.3 \pm 4.6$ & $208.1 \pm 9.6^{* \# \$}$ & $150.4 \pm 5.3^{* \# \$ \Phi}$ & $172.5 \pm 4.9^{* \# \$ \uparrow \dagger}$ \\
\hline $\begin{array}{l}\text { Serum TNF } \alpha \\
(\mathrm{pg} / \mathrm{ml})\end{array}$ & $24.1 \pm 2.4$ & $19.2 \pm 1.1$ & $20.9 \pm 1.2$ & $94.6 \pm 4.8^{* \# \$}$ & $61.8 \pm 3.8^{* \# \$}$ & $68.8 \pm 5.6^{* \# \$ \uparrow}$ \\
\hline Serum SOD (Unit/ml) & $359.6 \pm 5.9$ & $\begin{array}{c}368.4 \pm 3.2 \\
*\end{array}$ & $367 \pm 4.1$ & $170.1 \pm 3.5^{* \# \$}$ & $297.5 \pm 7^{* \# \$ \Phi}$ & $263.8 \pm 7.7^{* \# \$ 9 \dagger}$ \\
\hline Serum MDA (nmol/ml) & $11.3 \pm 0.3$ & $10.8 \pm 0.1$ & $11.1 \pm 0.1$ & $22.9 \pm 0.2^{* \# \$}$ & $15.9 \pm 0.3^{* \# \$ \Phi}$ & $18.7 \pm 0.7^{* \# \$ \uparrow}$ \\
\hline
\end{tabular}

Data was expressed as Mean \pm SD. ${ }^{*} P<0.05$ in comparison with lean non-diabetic sedentary group. ${ }^{\#} P<0.05$ in comparison with lean non-diabetic exercised group. ${ }^{\$} P<0.05$ in comparison with lean non-diabetic adropin treated group. ${ }^{\uparrow} P<0.05$ in comparison with obese diabetic sedentary group. ${ }^{\dagger} P<0.05$ in comparison with obese diabetic exercised group. BW: body weight, WD: weight difference (the difference between final and initial body weight), BMI: body mass index, HOMA-IR: homeostasis model assessment of insulin resistance index, TC: total cholesterol, TG: triglycerides, HDL: high-density lipoprotein, LDL: low-density lipoprotein, TNF $\alpha$ : tumor necrosis factor alpha, SOD: superoxide dismutase, MDA: malondialdehyde.

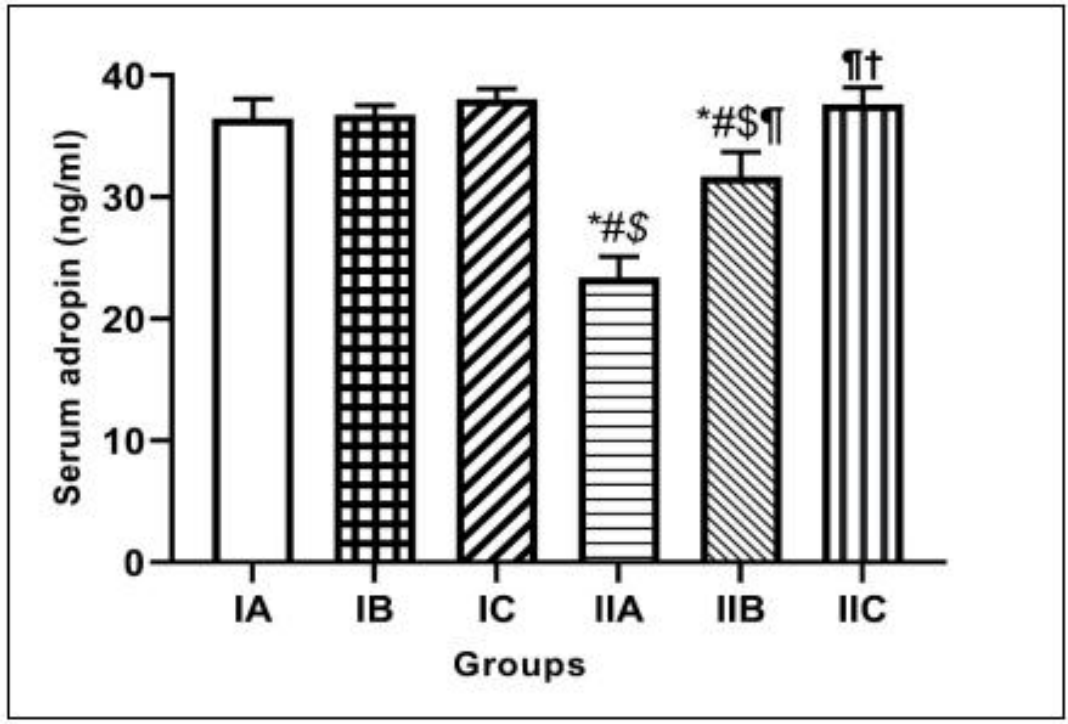

Figure 1: Serum adropin level $(\mathrm{ng} / \mathrm{ml})$ changes among different groups

Data was expressed as Mean $\pm \mathrm{SD}$. ${ }^{*} \mathrm{P}<0.001$ in comparison with lean non-diabetic sedentary group (IA). $\# \mathrm{P}<0.001$ in comparison with lean non-diabetic exercised group (IB). $\$ \mathrm{P}<0.001$ in comparison with lean non-

These results confirmed that moderate swimming exercise training and exogenous adropin treatment improved thyroid function changes that occurred in obese diabetic sedentary rats.

Effect of exercise training and exogenous adropin treatment on testicular function changes in obese diabetic rats (table 3): In obese diabetic sedentary group, a significant $(\mathrm{P}<0.001)$ decrease was reported in serum levels of (FSH, LH and testosterone), and in epididymal sperm (count and motility) in comparison to those in the lean non- diabetic adropin treated group (IC). $\mathbb{\Psi}(\mathbf{P}<0.001$ in comparison with obese diabetic sedentary group (IIA). $\dagger \mathrm{P}<0.001$ in comparison with obese diabetic exercised group (IIB). IIC: Obese diabetic adropin treated group.

diabetic sedentary group. These results emphasized that testicular function was disturbed in obese diabetic sedentary rats.

On either performing a moderate swimming exercise training (in obese diabetic exercised group) or exogenous adropin treatment (in obese diabetic adropin treated group); serum levels of (FSH, LH and testosterone), and epididymal sperm (count and motility) were significantly $(\mathrm{P}<0.001)$ increased in comparison with that in obese diabetic sedentary group. 
Table 3: Thyroid and testicular function changes among different groups

\begin{tabular}{|c|c|c|c|c|c|c|}
\hline Group & \multicolumn{3}{|c|}{ Group I (Lean Non-diabetic) } & \multicolumn{3}{|c|}{ Group II (Obese Diabetic) } \\
\hline Parameter & $\begin{array}{l}\text { Sedentary } \\
\text { (IA) }\end{array}$ & $\begin{array}{l}\text { Exercised } \\
\text { (IB) }\end{array}$ & $\begin{array}{l}\text { Adropin } \\
\text { treated (IC) }\end{array}$ & $\begin{array}{l}\text { Sedentary } \\
\text { (IIA) }\end{array}$ & $\begin{array}{l}\text { Exercised } \\
\text { (IIB) }\end{array}$ & $\begin{array}{c}\text { Adropin } \\
\text { treated (IIC) }\end{array}$ \\
\hline Serum TSH $(\mu \mathrm{IU} / \mathrm{L})$ & $2.74 \pm 0.06$ & $2.72 \pm 0.05$ & $2.73 \pm 0.05$ & $\begin{array}{c}17.78 \pm 0.27^{*} \\
\text { \#\$ }\end{array}$ & $10.63 \pm 0.18^{* \#}$ & $13.32 \pm 0.14^{* \# \$ \uparrow}$ \\
\hline Serum T4 ( $\mu \mathrm{g} / \mathrm{dl})$ & $5.21 \pm 0.06$ & $5.22 \pm 0.04$ & $5.22 \pm 0.05$ & $2.31 \pm 0.06^{* \# \$}$ & $3.98 \pm 0.1^{* \# \$}$ & $3.42 \pm 0.09^{* \# \$ \uparrow \dagger}$ \\
\hline Serum T3 (ng/ml) & $1.27 \pm 0.05$ & $1.26 \pm 0.06$ & $1.27 \pm 0.05$ & $0.37 \pm 0.03^{* \# \$}$ & $0.82 \pm 0.05^{* \# \$}$ & $0.62 \pm 0.06^{* \# \$ \uparrow \dagger}$ \\
\hline Serum FSH (ng/ml) & $6.37 \pm 0.04$ & $6.39 \pm 0.03$ & $6.4 \pm 0.01$ & $4.5 \pm 0.08^{* \# \$}$ & $5.51 \pm 0.1^{* \# \$ \Phi}$ & $5.1 \pm 0.06^{* \# \$ \uparrow \dagger}$ \\
\hline Serum LH (ng/ml) & $6.13 \pm 0.07$ & $6.13 \pm 0.07$ & $6.13 \pm 0.06$ & $4.32 \pm 0.06^{* \# \$}$ & $5.26 \pm 0.05^{* \# \$}$ & $4.66 \pm 0.08^{* \# \$ \uparrow \dagger}$ \\
\hline $\begin{array}{ll}\text { Serum } & \text { Testosterone } \\
(\mathrm{ng} / \mathrm{ml})\end{array}$ & $4.19 \pm 0.06$ & $4.18 \pm 0.06$ & $4.19 \pm 0.03$ & $2.52 \pm 0.06^{* \# \$}$ & $3.38 \pm 0.03^{* \# \$}$ & $3.03 \pm 0.1^{* \# \$ \uparrow \dagger}$ \\
\hline $\begin{array}{l}\text { Epididymal sperm } \\
\text { count (million/ml) }\end{array}$ & $\begin{array}{c}43.32 \pm 1.3 \\
8 \\
\end{array}$ & $43.19 \pm 1.32$ & $43.65 \pm 0.66$ & $\begin{array}{c}29.71 \pm 0.54^{*} \\
\# \$\end{array}$ & $\begin{array}{c}38.23 \pm 0.57^{* \#} \\
\$ \uparrow\end{array}$ & $34.84 \pm 0.76^{* \# \$ \uparrow}$ \\
\hline $\begin{array}{ll}\text { Epididymal } & \text { sperm } \\
\text { motility }(\%) & \\
\end{array}$ & $\begin{array}{c}65.76 \pm 1.0 \\
9 \\
\end{array}$ & $65.16 \pm 0.75$ & $65.1 \pm 0.85$ & $\begin{array}{c}48.76 \pm 0.37^{*} \\
\text { \#\$ }\end{array}$ & $\begin{array}{c}56.68 \pm 0.52^{* \#} \\
\$ \uparrow\end{array}$ & $52.22 \pm 0.42^{* \# \$ 9 \dagger}$ \\
\hline $\begin{array}{l}\text { Epididymal deformed } \\
\text { sperm }(\%)\end{array}$ & $1.6 \pm 0.04$ & $1.55 \pm 0.06$ & $1.58 \pm 0.05$ & $1.6 \pm 0.05$ & $1.58 \pm 0.04$ & $1.59 \pm 0.04$ \\
\hline
\end{tabular}

Data was expressed as Mean \pm SD. ${ }^{*} P<0.001$ in comparison with lean non-diabetic sedentary group. ${ }^{\#} P<0.001$ in comparison with lean non-diabetic exercised group. ${ }^{\$} P<0.001$ in comparison with lean non-diabetic adropin treated group. ${ }^{\sharp} P<0.001$ in comparison with

These results confirmed that exercise training and exogenous adropin treatment deteriorated the testicular function changes that occurred in obese diabetic sedentary rats.

Correlations between serum level of adropin and some biochemical parameters within the obese diabetic groups (table 4 and Fig.2): Correlations within the obese diabetic sedentary group between serum adropin and different studied parameters showed negative associations with weight difference ( $\mathrm{r}=-0.84, \mathrm{P}<0.01)$, $\mathrm{BMI}(\mathrm{r}=-0.92, \mathrm{P}<0.01)$, serum glucose $(\mathrm{r}=-0.93, \mathrm{P}<0.001)$, HOMA-IR $(\mathrm{r}=-$ $0.84, \mathrm{P}<0.01)$, serum TC $(\mathrm{r}=-0.91, \mathrm{P}<0.01)$, serum $\mathrm{TNF} \alpha(\mathrm{r}=-0.96, \mathrm{P}<0.001)$ and serum TSH $(\mathrm{r}=-0.9$, $\mathrm{P}<0.01$ ), but, positive correlations were recorded with serum HDL $(\mathrm{r}=0.94, \mathrm{P}<0.001)$, serum SOD $(\mathrm{r}=0.85, \mathrm{P}<0.01)$, serum $\mathrm{T} 4(\mathrm{r}=0.8, \mathrm{P}<0.05)$, serum LH $(r=0.95, P<0.001)$, serum testosterone $(r=0.93$, $\mathrm{P}<0.001)$ and epididymal sperm count $(\mathrm{r}=0.8$, $\mathrm{P}<0.05)$.

On the other hand, within the obese diabetic exercised group, negative associations were reported between serum adropin and weight obese diabetic sedentary group. ${ }^{\dagger} P<0.001$ in comparison with obese diabetic exercised group. TSH: thyroid stimulating hormone, T4: thyroxine, T3: triiodothyronine, $\mathrm{FSH}$, follicle stimulating hormone, LH: luteinizing hormone.

difference $\quad(\mathrm{r}=-0.89, \quad \mathrm{P}<0.01), \quad$ BMI $\quad(\mathrm{r}=-0.93$, $\mathrm{P}<0.001)$, serum glucose $(\mathrm{r}=-0.73, \quad \mathrm{P}<0.05)$, HOMA- IR $(\mathrm{r}=-0.85, \mathrm{P}<0.01)$, serum TC $(\mathrm{r}=-0.83$, $\mathrm{P}<0.05)$, serum $\mathrm{TNF} \alpha(\mathrm{r}=-0.81, \mathrm{P}<0.05)$ and serum TSH ( $\mathrm{r}=-0.97, \mathrm{P}<0.001$ ), but, positive correlations were found with serum HDL $(\mathrm{r}=0.87, \mathrm{P}<0.01)$, serum SOD $(\mathrm{r}=0.98, \mathrm{P}<0.001)$, serum $\mathrm{T} 4(\mathrm{r}=0.86$, $\mathrm{P}<0.01)$, serum LH $(\mathrm{r}=0.87, \quad \mathrm{P}<0.01)$, serum testosterone $(\mathrm{r}=0.9, \mathrm{P}<0.01)$ and epididymal sperm count $(\mathrm{r}=0.84, \mathrm{P}<0.01)$.

Also, within the obese diabetic adropin treated group, negative correlations were found between serum adropin and weight difference $(\mathrm{r}=-0.74$, $\mathrm{P}<0.05)$, BMI $(\mathrm{r}=-0.91, \mathrm{P}<0.01)$, serum glucose $(\mathrm{r}=-$ $0.95, \quad \mathrm{P}<0.001), \quad$ HOMA-IR $\quad(\mathrm{r}=-0.92, \quad \mathrm{P}<0.01)$, serum TC $(r=-0.87, \mathrm{P}<0.01)$, serum TNF $\alpha(r=-0.92$, $\mathrm{P}<0.01)$ and serum TSH $(\mathrm{r}=-0.89, \mathrm{P}<0.01)$, but, positive correlations were recorded with serum HDL $\quad(r=0.9, \quad \mathrm{P}<0.01)$, serum SOD $(\mathrm{r}=0.96$, $\mathrm{P}<0.001)$, serum $\mathrm{T} 4(\mathrm{r}=0.97, \mathrm{P}<0.001)$, serum $\mathrm{LH}$ $(\mathrm{r}=0.91, \quad \mathrm{P}<0.01)$, serum testosterone $\quad(\mathrm{r}=0.93$, $\mathrm{P}<0.001)$ and epididymal sperm count $(\mathrm{r}=0.89$, $\mathrm{P}<0.01)$. 
Table 4: Pearson's correlation coefficient ( $r$ ) between serum level of adropin and some biochemical parameters within the obese diabetic groups (sedentary, exercised and adropin treated)

\begin{tabular}{|l|c|c|c|c|c|c|}
\hline \multirow{3}{*}{ Parameter } & \multicolumn{9}{|c|}{ Serum adropin } \\
\cline { 2 - 7 } & \multicolumn{2}{|c|}{ Obese diabetic sedentary } & \multicolumn{2}{c|}{ Obese diabetic exercised } & \multicolumn{2}{c|}{$\begin{array}{c}\text { Obese diabetic adropin } \\
\text { treated }\end{array}$} \\
\cline { 2 - 7 } & $\mathrm{r}$ & $\mathrm{P}$ & $\mathrm{r}$ & $\mathrm{P}$ & $\mathrm{r}$ & $\mathrm{P}$ \\
\hline WD & -0.84 & $<0.01$ & -0.89 & $<0.01$ & -0.74 & $<0.05$ \\
\hline BMI & -0.92 & $<0.01$ & -0.93 & $<0.001$ & -0.91 & $<0.01$ \\
\hline Serum glucose & -0.93 & $<0.001$ & -0.73 & $<0.05$ & -0.95 & $<0.001$ \\
\hline HOMA-IR & -0.84 & $<0.01$ & -0.85 & $<0.01$ & -0.92 & $<0.01$ \\
\hline Serum TC & -0.91 & $<0.01$ & -0.83 & $<0.05$ & -0.87 & $<0.01$ \\
\hline Serum HDL & 0.94 & $<0.001$ & 0.87 & $<0.01$ & 0.9 & $<0.01$ \\
\hline Serum TNF & -0.96 & $<0.001$ & -0.81 & $<0.05$ & -0.92 & $<0.01$ \\
\hline Serum SOD & 0.85 & $<0.01$ & 0.98 & $<0.001$ & 0.96 & $<0.001$ \\
\hline Serum TSH & -0.9 & $<0.01$ & -0.97 & $<0.001$ & -0.89 & $<0.01$ \\
\hline Serum T4 & 0.8 & $<0.05$ & 0.86 & $<0.01$ & 0.97 & $<0.001$ \\
\hline Serum LH & 0.95 & $<0.001$ & 0.87 & $<0.01$ & 0.91 & $<0.01$ \\
\hline Serum testosterone & 0.93 & $<0.001$ & 0.9 & $<0.01$ & 0.93 & $<0.001$ \\
\hline Epididymal sperm count & 0.8 & $<0.05$ & 0.84 & $<0.01$ & 0.89 & $<0.01$ \\
\hline
\end{tabular}

$P<0.05$ indicated statistical significance. WD: index, TC: total cholesterol, HDL: high density weight difference (the difference between final and lipoprotein, TNF $\alpha$ tumor necrosis factor alpha, SOD: initial body weight), BMI: body mass index, HOMA-IR: $\quad$ superoxide dismutase, TSH: thyroid stimulating hormone, homeostasis model assessment of insulin resistance T4: thyroxine, LH: luteinizing hormone.

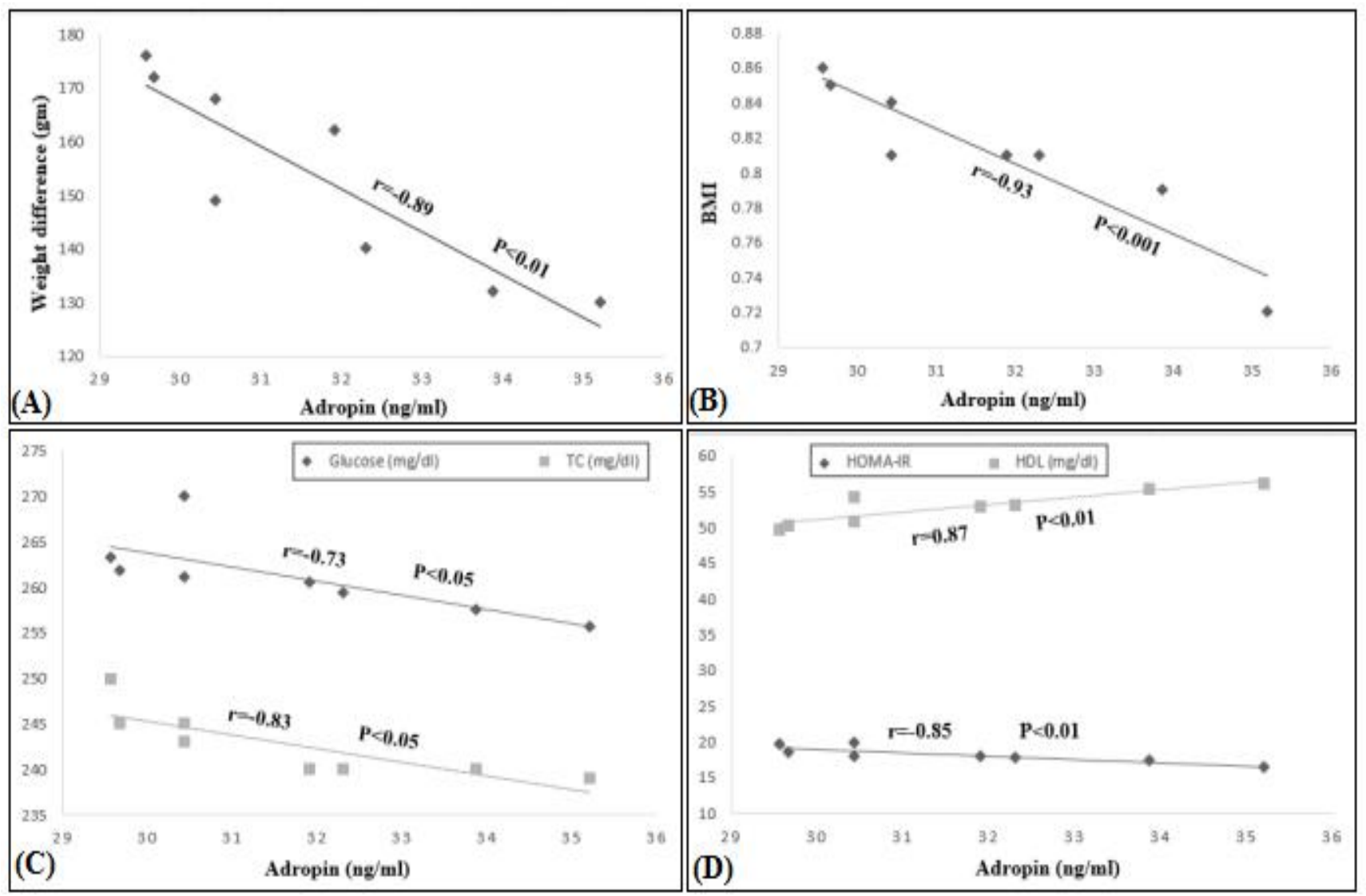



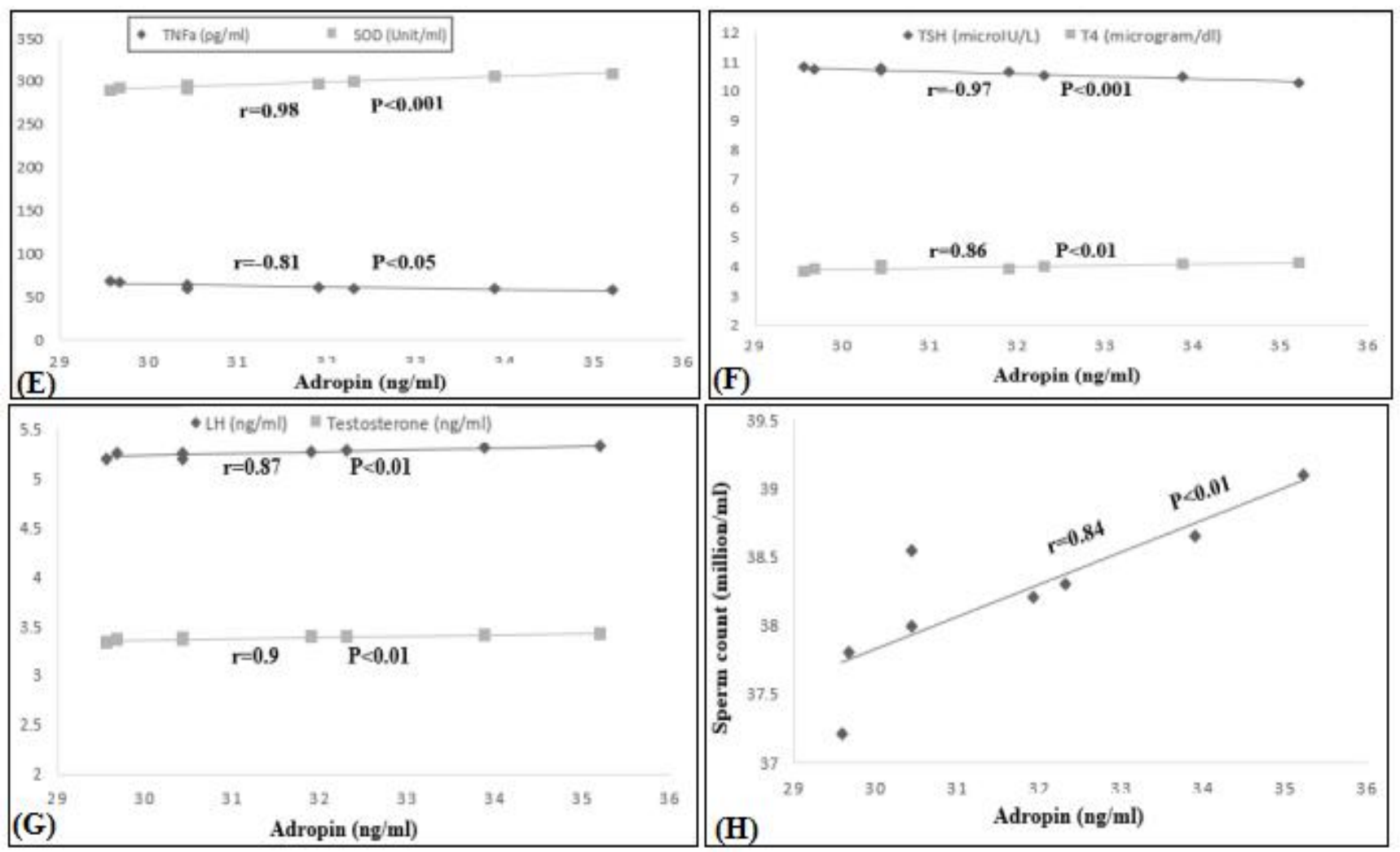

Figure 2: Pearson's correlation coefficient (r)

between serum levels of adropin and each of, weight difference (A); BMI (B); glucose and TC (C); HDL and HOMA-IR (D); SOD and TNF $\alpha$; TSH and T4 (F); LH and testosterone $(\mathrm{G})$; and, sperm count $(\mathrm{H})$ within obese diabetic exercised rats. BMI: body mass index, TC: total cholesterol, HDL: high density

\section{Discussion}

In this study, we investigated the effect of moderate swimming exercise training and adropin treatment on thyroid and testicular function changes that occurred in obese type 2 diabetic rats. Obesity was confirmed in obese diabetic groups by the significant increase in final body weight, weight difference and final BMI occurred in comparison to that of the lean non-diabetic groups. These changes were deteriorated by performing exercise training (in obese diabetic exercised group) and by exogenous adropin treatment (in obese diabetic adropin treated group).

Also, negative correlations within the obese diabetic groups were recorded between serum adropin and both, weight difference and BMI which confirmed that exercise training and adropin treatment could combat obesity which was supported by $\mathrm{H}$ Zhang, et al. ${ }^{[21]}$ who reported that lipoprotein, HOMA-IR: homeostasis model assessment of insulin resistance index, SOD: superoxide dismutase, TNFa:tumor necrosis factor alpha, TSH: thyroid stimulating hormone, T4: thyroxine, LH: luteinizing hormone.

moderate exercise training significantly reduced body weight and BMI in obese adolescents, and they confirmed the presence of a negative correlation between adropin serum level and BMI.

Our results showed a significant decrease in serum adropin level in both obese diabetic sedentary and obese diabetic exercised rats, in comparison with the lean non-diabetic rats which indicated that adropin may play a role in the pathophysiological changes that occurred in obese diabetic rats which was in agree with $\mathrm{M}$ Topuz, et al. ${ }^{[35]}$, L Wu, et al. ${ }^{[36]}$, R Akcilar, et al. ${ }^{[5]}$ and H Zhang, et al. [21]. With a moderate exercise training (in obese diabetic exercised group), serum adropin levels were significantly increased in comparison to that in obese diabetic sedentary group which may be a mechanism by which a moderate exercise training combatted the pathophysiological changes occurred in obese diabetic rats. This was supported by $\mathrm{S}$ Fujie, et al. ${ }^{[37]}$ and $\mathrm{H}$ Zhang, et al. ${ }^{[21]}$ who reported 
a significant increase in serum adropin in obese adolescents by an exercise intervention and they owed this to increased its expression in endothelial cells.

Incidence of insulin resistance in obese diabetic groups in our study was confirmed by the significant increase in serum levels of both glucose and insulin, and value of HOMA-IR in comparison with that of the lean non-diabetic groups which was supported by R Akcilar, et al. ${ }^{[5]}$. With moderate exercise training (in obese diabetic exercised group) and exogenous adropin treatment (in obese diabetic adropin treated group), insulin sensitivity was significantly improved which was supported by KG Kumar, et al. ${ }^{[1]}$ and $\mathrm{R}$ Akcilar, et al. [5] who reported that i.p. adropin administration significantly decreased both blood glucose and HOMA-IR value.

Also, S Terada, et al. ${ }^{[38]}$, G Boaventura, et al. [39], A Garcia-Hermoso, et al. [40], OA EL-Gohary [41], H MOUSTAFA ${ }^{[25]}$ and $\mathrm{H}$ Zhang, et al. [21] stated that exercise training induced a significant deterioration in insulin resistance in obese rats and they referred the insulin sensitizing effects of exercise training to the increased skeletal muscle activity of both glucose transporter (GLUT4) and hexokinase, and to the increased hepatic insulin clearance.

Moreover, negative associations within the obese diabetic groups were found between serum adropin and both serum glucose level and HOMAIR value which was in agree with B Yildirim, et al. ${ }^{[42]}$ and $\mathrm{H}$ Zhang, et al. ${ }^{[21]}$ who found a negative correlation between serum adropin and both serum insulin and HOMA-IR, but, a positive association with serum HDL. In accordance with our results, $\mathrm{S}$ Gao, et al. ${ }^{[43]}$ declared that obese mice treated with adropin had an improvement in glucose tolerance, insulin resistance and fuel selection for carbohydrate over fat utilization and they added that skeletal muscle was the key organ that mediated the adropin whole-body effects.

Our results declared a significant disturbance in lipid metabolism in obese diabetic rats in the form of a significant increase in serum levels of TC, TG and LDL with a significant decrease in serum levels of HDL in comparison to that of the lean nondiabetic groups which were similar to results of studies conducted by X-J Zhang, et al. ${ }^{[44]}$ and R
Akcilar, et al. ${ }^{[5]}$. These changes were reversed by both moderate exercise training (in obese diabetic exercised rats) and with exogenous adropin treatment (in obese diabetic adropin treated rats) which confirmed improved lipid metabolism and this was supported by $\mathrm{G}$ Boaventura, et al. ${ }^{[39]}, \mathrm{H}$ MOUSTAFA ${ }^{[25]}$ and $H$ Zhang, et al. [21] who emphasized that exercise training in obese rats deteriorated the changes in the serum lipid profile.

Also, S Gao, et al. ${ }^{[45]}$, YF Otero, et al. ${ }^{[46], ~ S ~}$ Gao, et al. ${ }^{[43]}$ and R Akcilar, et al. ${ }^{[5]}$ found that adropin treatment reduced fatty acid oxidation but increased glucose utilization in skeletal muscles in obese mice which resulted in improved glucose homeostasis and insulin resistance. Within the obese diabetic groups, serum adropin levels were negatively correlated with serum TC, but positively correlated with serum HDL which was in agree with AA Butler, et al. ${ }^{[47]}$ and B Yildirim, et al. ${ }^{[42]}$.

Our results declared presence of inflammatory reactions and oxidative stress in obese diabetic groups as evidenced by the significant increase in serum levels of TNF $\alpha$ and MDA and the significant decrease in serum SOD levels in comparison with that of the lean non-diabetic groups which was in line with F Ribeiro, et al. ${ }^{[48]}$, T Fujita, et al. ${ }^{[49]}$ and $\mathrm{Y}-\mathrm{N}$ Liu, et al. ${ }^{[50]}$ who confirmed that increased serum $\mathrm{TNF} \alpha$ is the cause of insulin resistance occurred in obese diabetic rats. Also, Y-F Jia, et al. ${ }^{[7]}$ stated that MDA is an aldehyde produced by lipid peroxidation in response to exposure to free radicals and its increase indicated cell membrane damage.

Moreover, D Atilgan, et al. ${ }^{[51]}$ referred the oxidative stress associated with obesity to the disturbance in lipid metabolism with increased serum free and unsaturated fatty acids that were exposed to attacks by reactive oxygen species that decreased SOD levels and increased MDA. Moreover, S Furukawa, et al. ${ }^{[52]}$ explained the increased oxidative stress in obese diabetic rats by the elevation in serum levels of inflammatory cytokines.

With moderate exercise training (in obese diabetic exercised group) and exogenous adropin treatment (in obese diabetic adropin treated group), inflammatory reaction and oxidative stress were deteriorated as evidenced by the significant reduction of both serum TNF $\alpha$ and MDA levels and the significant increase in serum SOD levels in 
comparison to those in obese diabetic sedentary group which confirmed that exercise training and adropin treatment had both anti-inflammatory and antioxidant activities on obese diabetic rats. This was supported by $\mathrm{T}$ Christiansen, et al. ${ }^{[53]}$ who declared that exercise training in obese rats ameliorated hypoxia of adipose tissue and diminished its local inflammation decreasing serum $\mathrm{TNF} \alpha$. Also, R Akcilar, et al. ${ }^{[5]}$ confirmed that adropin had a significant anti-diabetic effect through decreasing the inflammatory cytokines in type 2 diabetic rats. Within the obese diabetic groups, serum adropin levels were negatively correlated with serum $\mathrm{TNF} \alpha$ and positively associated with serum SOD.

The study results showed a significant increase in serum levels of TSH but, a significant decrease in serum levels of T3 and T4 in obese diabetic groups in comparison to those of the lean non-diabetic groups which confirmed occurrence of hypothyroidism which was in agree with $\mathrm{C}$ Anil, et al. [54] and M Mishra, et al. ${ }^{[55]}$ who stated that diabetes mellitus affected thyroid function and added that uncontrolled type 2 diabetic patients had a significant elevation in serum levels of TSH and they owed this to the increase in both fat mass and insulin resistance which increased serum leptin that acted directly on leptin receptors on thyrotropin releasing hormone neurons increasing thyrotropin releasing hormone secretion and consequently TSH release from the anterior pituitary. Also, J Rezzonico, et al. [56] recorded an association between both insulin resistance and thyroid dysfunction. Moreover, G Akbaba, et al. [17] declared that adropin levels were significantly decreased in hypothyroidism which was a finding in obese diabetic rats in our study.

With moderate exercise training (in obese diabetic exercised group) and exogenous adropin treatment (in obese diabetic adropin treated group), thyroid function was improved as evidenced by the significant reduction in serum TSH levels and the significant increase in serum levels of T3 and T4 in comparison with those in obese diabetic sedentary group which was supported by RJ McMurray, DA [57] and R Arkader, et al. [58] who reported that exercise training increased serum levels of T3 and T4. Within the obese diabetic groups, serum adropin levels were negatively correlated with serum TSH, but positively associated with serum T4.

In obese diabetic groups, there was a disturbed testicular function as evidenced by the significant decrease in serum levels of FSH, LH and testosterone, and in both epididymal sperm count and motility in comparison to those of the lean nondiabetic groups which was supported by E Camacho, et al. ${ }^{[59]}$, MNT Fui, et al. ${ }^{[60]}$, SAA El-Kaream, et al. ${ }^{[61]}$ and Y-F Jia, et al. ${ }^{[7]}$ who found a lower serum testosterone levels in obese males. Also, JE Chavarro, et al. ${ }^{[12]}$, O Tunc, et al. ${ }^{[62]}$ and $\mathrm{N}$ Sermondade, et al. ${ }^{[14]}$ found that increased BMI was associated with a significant decrease in sperm count.

Moreover, a review written by Y-F Jia, et al. ${ }^{[7]}$ found that up to 2015, reduced sperm motility was reported in 13 of 35 articles, while a decreased sperm count with normal morphology was reported in 9 of 29 research papers. Furthermore, RM Vigueras-Villaseñor, et al. ${ }^{[63]}$ reported that rats fed a HFD from 21 to 90 days had a decreased sperm count. Also, C Li, et al. ${ }^{[64]}$, $\mathrm{H}$ Wagner, et al. ${ }^{[65]}$ and Y-F Jia, et al. ${ }^{[7]}$ stated that long-term obesity impaired spermatogenesis and they owed this to increased reactive oxygen species which induced damage to the sperm cell membranes (contained large amount of polyunsaturated fats), cell DNA, and mitochondria. Moreover, F Alhashem, et al. ${ }^{[66]}$ referred the obesity induced decrease in sperm count and motility to the decrease in serum FSH which decreased stem cell factor signaling increasing ghrelin expression in the testis causing sperm apoptosis. Furthermore, MR Nikoobakht, et al. [18] found that hypothyroidism significantly reduced sperm count and motility and this may explain the disturbance in testicular function observed in obese diabetic rats.

With moderate exercise training (in obese diabetic exercised group) and exogenous adropin treatment (in obese diabetic adropin treated group), testicular function changes were deteriorated as evidenced by the significant increase in serum levels of testosterone, and in epididymal sperm count and motility in comparison with those in obese diabetic sedentary group which was supported by LB Håkonsen, et al. ${ }^{[67]}$ and E Camacho, et al. [59] who declared that serum testosterone level, sperm count and motility were 
increased after reduction of weight in obese rats. Also, F Alhashem, et al. ${ }^{[66]}$ confirmed that exercise training combatted the deterioration in testicular function with obesity by improving serum level of testosterone and semen parameters through decreasing testicular ghrelin and increasing testicular stem cell factor. Moreover, exercise training may improve testicular function in type 2 diabetic rats through its antioxidant activity as evidenced also by JD Botezelli, et al. [68] who reported that swim training for 8 weeks diminished lipid peroxidation and increased SOD enzyme activity.

According to our results, the improved testicular function with adropin and exercise training could be referred to the significant deterioration in the changes in the thyroid function occurred with obese diabetic rats which was supported by C Carani, et al. ${ }^{[69]}$ who stated that treatment of thyroid dysfunction improved testicular function. A positive association was recorded within the obese diabetic groups between serum adropin and each of serum LH, serum testosterone and epididymal sperm count.

Along this study, we noticed that adropin levels were significantly decreased and correlated to metabolic, thyroid and testicular changes within obese diabetic rats. But, with exogenous adropin treatment such changes were significantly improved. Also, we detected that moderate exercise training significantly enhanced serum adropin levels (although they did not reach the normal values) in obese diabetic rats with more significant improvement in metabolic, thyroid and testicular function than with exogenous adropin treatment which may confirm that increasing serum levels of adropin in obese diabetic rats could be a mechanism by which moderated exercise training combatted such metabolic, thyroid and testicular changes. This was in agree with S Aydin, et al. ${ }^{[2]}$ and C-M Wong, et al. ${ }^{3]}$ who reported that adropin is expressed in the rat skeletal muscle. Study limitations include, sample size which should be larger. Also, we used a rat model of T2DM and the results may differ from that in human.

\section{Conclusion}

Exercise training and adropin treatment deteriorated thyroid and testicular function changes occurred in obese diabetic rats through several mechanisms including reduction of BMI, improvement of glucose and lipid metabolism, increase in insulin sensitivity and through their antiinflammatory and antioxidant effects. Also, the improvement in testicular function changes with both adropin treatment and exercise training could be partly referred to the improvement in thyroid function changes that occurred in obese diabetic rats.

Moreover, moderate exercise training achieved its effects partly through increasing serum adropin level which could be used as a novel biomarker for testicular function. Further studies are requested to confirm our results.

\section{Conflict of Interest}

Authors declare absence of any conflict of interest with this study.

\section{Acknowledgement}

Authors provide their sincere gratitude to Department of Physiology, Faculty of Medicine, Zagazig University for supporting achievement of this study.

\section{References}

1 Kumar KG, Trevaskis JL, Lam DD, Sutton GM, Koza RA, Chouljenko VN, Kousoulas KG, Rogers PM, Kesterson RA, Thearle M, Ferrante AW, Jr., Mynatt RL, Burris TP, Dong JZ, Halem HA, Culler MD, Heisler LK, Stephens JM, Butler AA. Identification of adropin as a secreted factor linking dietary macronutrient intake with energy homeostasis and lipid metabolism. Cell Metab 2008; 8(6): 468-481 DOI: 10.1016/j.cmet.2008.10.011

2 Aydin S, Kuloglu T, Aydin S, Eren MN, Yilmaz M, Kalayci M, Sahin I, Kocaman N, Citil C, Kendir Y. Expression of adropin in rat brain, cerebellum, kidneys, heart, liver, and pancreas in streptozotocin-induced diabetes. 
Mol Cell Biochem 2013; 380(1-2): 73-81 DOI: 10.1007/s11010-013-1660-4

3 Wong CM, Wang Y, Lee JT, Huang Z, Wu D, $\mathrm{Xu} \mathrm{A}$, Lam KS. Adropin is a brain membranebound protein regulating physical activity via the NB-3/Notch signaling pathway in mice. $\boldsymbol{J}$ Biol Chem 2014; 289(37): 25976-25986 DOI: 10.1074/jbc.M114.576058

4 Gao S, Stevens JR, Butler AA. Adropin - a circulating factor in metabolic control or a drop in the ocean? Expert Rev Endocrinol Metab 2016; 11(3): 239-241 DOI: 10.1080/17446651.2016.1175938

5 Akcilar R, Kocak FE, Simsek H, Akcilar A, Bayat Z, Ece E, Kokdasgil H. Antidiabetic and hypolipidemic effects of adropinin streoptozotocin-induced type 2 diabetic rats. Bratisl Lek Listy 2016; 117(2): 100-105 [PMID: 26830041]

6 Ganesh Kumar K, Zhang J, Gao S, Rossi J, McGuinness OP, Halem HH, Culler MD, Mynatt RL, Butler AA. Adropin deficiency is associated with increased adiposity and insulin resistance. Obesity (Silver Spring) 2012; 20(7): 1394-1402 DOI: $10.1038 /$ oby.2012.31

7 Jia YF, Feng Q, Ge ZY, Guo Y, Zhou F, Zhang KS, Wang XW, Lu WH, Liang XW, Gu YQ. Obesity impairs male fertility through long-term effects on spermatogenesis. BMC Urol 2018; 18(1): 42 DOI: $\underline{10.1186 / \mathrm{s} 12894-}$ 018-0360-5

8 MacDonald AA, Herbison GP, Showell M, Farquhar CM. The impact of body mass index on semen parameters and reproductive hormones in human males: a systematic review with meta-analysis. Hum Reprod Update 2010; 16(3): 293-311 DOI: 10.1093/humupd/dmp047

9 Aggerholm AS, Thulstrup AM, Toft G, Ramlau-Hansen $\mathrm{CH}$, Bonde JP. Is overweight a risk factor for reduced semen quality and altered serum sex hormone profile? Fertil Steril 2008; 90(3): 619-626 DOI: 10.1016/j.fertnstert.2007.07.1292

10 Duits FH, van Wely $M$, van der Veen F, Gianotten J. Healthy overweight male partners of subfertile couples should not worry about their semen quality. Fertil Steril 2010; 94(4): 1356-1359 [PMID: 19608174 DOI: 10.1016/j.fertnstert.2009.05.075]
11 Tsao CW, Liu CY, Chou YC, Cha TL, Chen $\mathrm{SC}$, Hsu CY. Exploration of the association between obesity and semen quality in a 7630 male population. PLoS One 2015; 10(3): e0119458 DOI: 10.1371/journal.pone.0119458

12 Chavarro JE, Toth TL, Wright DL, Meeker JD, Hauser R. Body mass index in relation to semen quality, sperm DNA integrity, and serum reproductive hormone levels among men attending an infertility clinic. Fertil Steril 2010; 93(7): 2222-2231 DOI: 10.1016/j.fertnstert.2009.01.100

13 Hammiche F, Laven JS, Twigt JM, Boellaard WP, Steegers EA, Steegers-Theunissen RP. Body mass index and central adiposity are associated with sperm quality in men of subfertile couples. Hum Reprod 2012; 27(8): 2365-2372 DOI: 10.1093/humrep/des177

14 Sermondade N, Faure C, Fezeu L, Levy R, Czernichow S, Obesity-Fertility Collaborative G. Obesity and increased risk for oligozoospermia and azoospermia. Arch Intern Med 2012; 172(5): 440-442 DOI: 10.1001/archinternmed.2011.1382

15 Ford ES, Bergmann MM, Kroger J, Schienkiewitz A, Weikert C, Boeing $\mathrm{H}$. Healthy living is the best revenge: findings from the European Prospective Investigation Into Cancer and Nutrition-Potsdam study. Arch Intern Med 2009; 169(15): 1355-1362 DOI: 10.1001/archinternmed.2009.237

16 Han C, He X, Xia X, Li Y, Shi X, Shan Z, Teng W. Subclinical Hypothyroidism and Type 2 Diabetes: A Systematic Review and Meta-Analysis. PLoS One 2015; 10(8): e0135233 [PMID: 26270348 DOI: 10.1371/journal.pone.0135233]

17 Akbaba, G.; Emine, K.; Çinar, N.; Edgünlü, T.\&Tosun, K. Comparison of Serum Netrin-1. Nesfatin-1 and Adropin Levels in Subclinical and Overt Hypothyroidism, Turkish Journal of Endocrinology and Metabolism, 2018; 22(2):55-62. DOI:10.25179/tjem.20182202P146

18 Nikoobakht MR, Aloosh M, Nikoobakht N, Mehrsay AR, Biniaz F, Karjalian MA. The role of hypothyroidism in male infertility and erectile dysfunction. Urol $\boldsymbol{J}$ 2012; 9(1): $405-$ 409 [PMID: 22395839] 
19 Roberts CK, Vaziri ND, Barnard RJ. Effect of diet and exercise intervention on blood pressure, insulin, oxidative stress, and nitric oxide availability. Circulation 2002; 106(20): 2530-2532 [PMID: 12427646 DOI: 10.1161/01.cir.0000040584.91836.0d]

20 Moinuddin I, Leehey DJ. A comparison of aerobic exercise and resistance training in patients with and without chronic kidney disease. Adv Chronic Kidney Dis 2008; 15(1): 83-96 DOI: $\underline{10.1053 / \text { j.ackd.2007.10.004 }}$

21 Zhang H, Jiang L, Yang YJ, Ge RK, Zhou M, $\mathrm{Hu} \mathrm{H}$, Liu H, Cui J, Li LL, Dong YF, Cheng XS, Chen R, Li P. Aerobic exercise improves endothelial function and serum adropin levels in obese adolescents independent of body weight loss. Sci Rep 2017; 7(1): 17717 DOI: 10.1038/s41598-017-18086-3

22 Rahimi, E.; Zadeh, Y. M.\&Boostani, M. A. The effect of resistance training on thyroid hormones, Eur J Exp Biol, 2013; 3(2):443-447. https://pdfs.semanticscholar.org/2611/9903667 204e5479ee808c697600c72a766dd.pdf.

23 Srinivasan K, Viswanad B, Asrat L, Kaul CL, Ramarao P. Combination of high-fat diet-fed and low-dose streptozotocin-treated rat: a model for type 2 diabetes and pharmacological screening. Pharmacol Res 2005; 52(4): 313320 DOI: 10.1016/j.phrs.2005.05.004

24 Gibb AA, Epstein PN, Uchida S, Zheng Y, McNally LA, Obal D, Katragadda K, Trainor P, Conklin DJ, Brittian KR, Tseng MT, Wang J, Jones SP, Bhatnagar A, Hill BG. ExerciseInduced Changes in Glucose Metabolism Promote Physiological Cardiac Growth. Circulation 2017; 136(22): 2144-2157 DOI: 10.1161/CIRCULATIONAHA.117.028274

25 MOUSTAFA, H. Effect of Exercise on Inflammatory Cytokines, Lipid Profile and Glycemic Control in Normal and Obese Rats, Med j Cairo Univ, 2017; 85(6):2265-2273. http://medicaljournalofcairouniversity.net/hom e2/images/pdf/2017/September/b25.pdf.

26 Novelli EL, Diniz YS, Galhardi CM, Ebaid GM, Rodrigues HG, Mani F, Fernandes AA, Cicogna AC, Novelli Filho JL. Anthropometrical parameters and markers of obesity in rats. Lab Anim 2007; 41(1): 111119 DOI: $\underline{10.1258 / 002367707779399518}$
27 D. A. Silva ND J, Fernandes T, Soci UP, Monteiro AW, Phillips MI, EM DEO. Swimming training in rats increases cardiac MicroRNA-126 expression and angiogenesis. Med Sci Sports Exerc 2012; 44(8): 1453-1462 DOI: 10.1249/MSS.0b013e31824e8a36

28 Feng R, Wang L, Li Z, Yang R, Liang Y, Sun Y, Yu Q, Ghartey-Kwansah G, Sun Y, Wu Y, Zhang W, Zhou X, Xu M, Bryant J, Yan G, Isaacs $\mathrm{W}, \mathrm{Ma} \mathrm{J}, \mathrm{Xu} \mathrm{X} . \mathrm{A}$ systematic comparison of exercise training protocols on animal models of cardiovascular capacity. Life Sci 2019; 217: 128-140 DOI: 10.1016/j.1fs.2018.12.001

29 Rohling M, Herder C, Stemper T, Mussig K. Influence of Acute and Chronic Exercise on Glucose Uptake. J Diabetes Res 2016; 2016: 2868652 DOI: $10.1155 / 2016 / 2868652$

30 Friedewald WT, Levy RI, Fredrickson DS. Estimation of the concentration of low-density lipoprotein cholesterol in plasma, without use of the preparative ultracentrifuge. Clin Chem 1972; 18(6): 499-502 [PMID: 4337382]

31 Sun G, Bishop J, Khalili S, Vasdev S, Gill V, Pace D, Fitzpatrick D, Randell E, Xie YG, Zhang H. Serum visfatin concentrations are positively correlated with serum triacylglycerols and down-regulated by overfeeding in healthy young men. Am J Clin Nutr 2007; 85(2): 399-404 DOI: $\underline{10.1093 / \mathrm{ajcn} / 85.2 .399}$

32 Narayana K, D'Souza UJ, Rao KP. Effect of ribavirin on epididymal sperm count in rat. Indian J Physiol Pharmacol 2002; 46(1): $97-$ 101 [PMID: 12024964]

33 Vega SG, Guzman P, Garcia L, Espinosa J, Cortinas de Nava C. Sperm shape abnormality and urine mutagenicity in mice treated with niclosamide. Mutat Res 1988; 204(2): 269-276 DOI: $10.1016 / 0165-1218(88) 90099-7$

34 Khaki A, Fathiazad F, Nouri M, Khaki A, Maleki NA, Khamnei HJ, Ahmadi P. Beneficial effects of quercetin on sperm parameters in streptozotocin-induced diabetic male rats. Phytother Res 2010; 24(9): 1285 1291 DOI: $\underline{10.1002 / \text { ptr. } 3100}$

35 Topuz M, Celik A, Aslantas T, Demir AK, Aydin S, Aydin S. Plasma adropin levels predict endothelial dysfunction like flow- 
mediated dilatation in patients with type 2 diabetes mellitus. J Investig Med 2013; 61(8): 1161-1164

DOI:

10.2310/JIM.0000000000000003

36 Wu L, Fang J, Chen L, Zhao Z, Luo Y, Lin C, Fan L. Low serum adropin is associated with coronary atherosclerosis in type 2 diabetic and non-diabetic patients. Clin Chem Lab Med 2014; 52(5): 751-758 [PMID: 24323892 DOI: 10.1515/cclm-2013-0844]

37 Fujie S, Hasegawa N, Sato K, Fujita S, Sanada K, Hamaoka T, Iemitsu M. Aerobic exercise training-induced changes in serum adropin level are associated with reduced arterial stiffness in middle-aged and older adults. $\boldsymbol{A} \boldsymbol{m} \mathbf{J}$ Physiol Heart Circ Physiol 2015; 309(10): H1642-1647

DOI:

10.1152/ajpheart.00338.2015

38 Terada S, Yokozeki T, Kawanaka K, Ogawa K, Higuchi M, Ezaki O, Tabata I. Effects of highintensity swimming training on GLUT-4 and glucose transport activity in rat skeletal muscle. J Appl Physiol (1985) 2001; 90(6): 2019-2024 DOI: 10.1152/jappl.2001.90.6.2019

39 Boaventura G, Casimiro-Lopes G, PazosMoura CC, Oliveira E, Lisboa PC, Moura EG. Effects of running wheel training on adult obese rats programmed by maternal prolactin inhibition. J Endocrinol 2013; 219(1): 29-37 DOI: 10.1530/JOE-13-0102

40 Garcia-Hermoso A, Saavedra JM, Escalante Y, Sanchez-Lopez M, Martinez-Vizcaino V. Endocrinology and Adolescence: aerobic exercise reduces insulin resistance markers in obese youth: a meta-analysis of randomized controlled trials. Eur J Endocrinol 2014; 171(4): R163-171 [PMID: 24920290 DOI: 10.1530/EJE-14-0291]

41 EL-Gohary, O. A. Exercise Training Prevents Age-induced Insulin Resistance in Rats: Effect on Circulating Catecholamines, Inflammatory Cytokines and Skeletal Muscle Glut4 Transporters, American Journal of Biomedical Sciences 2017; 9(3):127-139. DOI:10.5099/aj170300127

42 Yildirim B, Celik O, Aydin S. Adropin: a key component and potential gatekeeper of metabolic disturbances in policystic ovarian syndrome. Clin Exp Obstet Gynecol 2014; 41(3): 310-312 [PMID: 24992783]

43 Gao S, McMillan RP, Zhu Q, Lopaschuk GD, Hulver MW, Butler AA. Therapeutic effects of adropin on glucose tolerance and substrate utilization in diet-induced obese mice with insulin resistance. Mol Metab 2015; 4(4): 310324 DOI: $10.1016 /$ j.molmet.2015.01.005

44 Zhang XJ, Deng YX, Shi QZ, He MY, Chen B, Qiu XM. Hypolipidemic effect of the Chinese polyherbal Huanglian Jiedu decoction in type 2 diabetic rats and its possible mechanism. Phytomedicine 2014; 21(5): 615-623 DOI: 10.1016/j.phymed.2013.11.004

45 Gao S, McMillan RP, Jacas J, Zhu Q, Li X, Kumar GK, Casals N, Hegardt FG, Robbins PD, Lopaschuk GD, Hulver MW, Butler AA. Regulation of substrate oxidation preferences in muscle by the peptide hormone adropin. Diabetes 2014; 63(10): 3242-3252 DOI: 10.2337/db14-0388

46 Otero YF, Stafford JM, McGuinness OP. Pathway-selective insulin resistance and metabolic disease: the importance of nutrient flux. J Biol Chem 2014; 289(30): 2046220469 DOI: $10.1074 /$ jbc.R114.576355

47 Butler AA, Tam CS, Stanhope KL, Wolfe BM, Ali MR, O'Keeffe M, St-Onge MP, Ravussin E, Havel PJ. Low circulating adropin concentrations with obesity and aging correlate with risk factors for metabolic disease and increase after gastric bypass surgery in humans. J Clin Endocrinol Metab 2012; 97(10): 37833791 DOI: $10.1210 /$ jc.2012-2194

48 Ribeiro F, Alves AJ, Duarte JA, Oliveira J. Is exercise training an effective therapy targeting endothelial dysfunction and vascular wall inflammation? Int J Cardiol 2010; 141(3): 214-221 DOI: $10.1016 /$ i.ijcard.2009.09.548

49 Fujita T, Hemmi S, Kajiwara M, Yabuki M, Fuke Y, Satomura A, Soma M. Complementmediated chronic inflammation is associated with diabetic microvascular complication. Diabetes Metab Res Rev 2013; 29(3): 220-226 [PMID: 23280928 DOI: 10.1002/dmrr.2380]

50 Liu YN, Jung JH, Park H, Kim H. Olive leaf extract suppresses messenger RNA expression of proinflammatory cytokines and enhances insulin receptor substrate 1 expression in the 
rats with streptozotocin and high-fat dietinduced diabetes. Nutr Res 2014; 34(5): 450457 DOI: $10.1016 /$ j.nutres.2014.04.007

51 Atilgan D, Parlaktas BS, Uluocak N, Erdemir F, Kilic S, Erkorkmaz U, Ozyurt H, Markoc F. Weight loss and melatonin reduce obesityinduced oxidative damage in rat testis. $\boldsymbol{A d \boldsymbol { d }}$ Urol 2013; 2013: 836121 DOI: $10.1155 / 2013 / 836121$

52 Furukawa S, Fujita T, Shimabukuro M, Iwaki M, Yamada Y, Nakajima Y, Nakayama O, Makishima M, Matsuda M, Shimomura I. Increased oxidative stress in obesity and its impact on metabolic syndrome. J Clin Invest 2004; 114(12): 1752-1761 DOI: 10.1172/JCI21625

53 Christiansen T, Paulsen SK, Bruun JM, Pedersen SB, Richelsen B. Exercise training versus diet-induced weight-loss on metabolic risk factors and inflammatory markers in obese subjects: a 12-week randomized intervention study. Am J Physiol Endocrinol Metab 2010; 298(4): E824-831 [PMID: 20086201 DOI: 10.1152/ajpendo.00574.2009]

54 Anil C, Akkurt A, Ayturk S, Kut A, Gursoy A. Impaired glucose metabolism is a risk factor for increased thyroid volume and nodule prevalence in a mild-to-moderate iodine deficient area. Metabolism 2013; 62(7): 970975 DOI: 10.1016/j.metabol.2013.01.009

55 Mishra, M.; Relatado-Sotto, M.; Panta, R.; Miyares, M.\&Solanki, R. Association of Diabetes Mellitus and Thyroid Disorders: A Metabolic Prospective, Asian Pac J Health Sci 2017; 4(3):253-262. DOI:10.21276/apjhs.2017.4.3.39

56 Rezzonico J, Rezzonico M, Pusiol E, Pitoia F, Niepomniszcze $H$. Introducing the thyroid gland as another victim of the insulin resistance syndrome. Thyroid 2008; 18(4): 461-464 DOI: $10.1089 /$ thy.2007.0223

57 Hackney AC, McMurray RG, Judelson DA, Harrell JS. Relationship between caloric intake, body composition, and physical activity to leptin, thyroid hormones, and cortisol in adolescents. Jpn J Physiol 2003; 53(6): 475479 DOI: $10.2170 /$ jjphysiol.53.475

58 Arkader,R.;Rosa,M.\&Moretti, G. Physiological Changes of Exercise of Thermogenesis,
Thyroid Homeostasis and Inflammation, Endocrinology and Metabolism International Journal, 2016; 3(4):55-64. DOI:10.15406/emij.2016.03.00055

59 Camacho EM, Huhtaniemi IT, O'Neill TW, Finn JD, Pye SR, Lee DM, Tajar A, Bartfai G, Boonen S, Casanueva FF, Forti G, Giwercman A, Han TS, Kula K, Keevil B, Lean ME, Pendleton N, Punab M, Vanderschueren D, Wu FC, Group E. Age-associated changes in hypothalamic-pituitary-testicular function in middle-aged and older men are modified by weight change and lifestyle factors: longitudinal results from the European Male Ageing Study. Eur J Endocrinol 2013; 168(3): 445-455 DOI: 10.1530/EJE-12-0890

60 Fui MN, Dupuis P, Grossmann M. Lowered testosterone in male obesity: mechanisms, morbidity and management. Asian J Androl 2014; 16(2): 223-231 DOI: 10.4103/1008$\underline{682 X .122365}$

61 El-Kaream, S. A. A.; El-Monem, S. A.; Mohassab, M.\&Khalil, G. I. Relationship between Testosterone Level, Serum Omentin-1 and Insulin Resistance in Obese Men, American Journal of Biomedical Sciences, 2015;7(3):134-147. DOI:10.5099/aj150300134

62 Tunc O, Bakos HW, Tremellen K. Impact of body mass index on seminal oxidative stress. Andrologia 2011; 43(2): 121-128 DOI: 10.1111/j.1439-0272.2009.01032.x

63 Vigueras-Villasenor RM, Rojas-Castaneda JC, Chavez-Saldana M, Gutierrez-Perez O, GarciaCruz ME, Cuevas-Alpuche O, Reyes-Romero MM, Zambrano E. Alterations in the spermatic function generated by obesity in rats. Acta Histochem 2011; 113(2): 214-220 [PMID: 20149418 DOI: $\underline{10.1016 / j . a c t h i s .2009 .10 .004]}$

64 Li CY, Dong ZQ, Lan XX, Zhang XJ, Li SP. [Endoplasmic reticulum stress promotes the apoptosis of testicular germ cells in hyperlipidemic rats]. Zhonghua Nan Ke Xue 2015; 21(5): 402-407 [PMID: 26117936]

65 Wagner H, Cheng JW, Ko EY. Role of reactive oxygen species in male infertility: An updated review of literature. Arab J Urol 2018; 16(1): 35-43 [PMID: 29713534 PMCID: PMC5922220 DOI: 10.1016/j.aju.2017.11.001] 
66 Alhashem F, Alkhateeb M, Sakr H, Alshahrani M, Alsunaidi M, Elrefaey H, Alessa R, Sarhan M, Eleawa SM, Khalil MA. Exercise protects against obesity induced semen abnormalities via downregulating stem cell factor, upregulating Ghrelin and normalizing oxidative stress. EXCLI J 2014; 13: 551-572

67 Hakonsen LB, Thulstrup AM, Aggerholm AS, Olsen J, Bonde JP, Andersen CY, Bungum M, Ernst EH, Hansen ML, Ernst EH, RamlauHansen CH. Does weight loss improve semen quality and reproductive hormones? Results from a cohort of severely obese men. Reprod Health 2011; 8: 24 DOI: 10.1186/1742-4755$\underline{8-24}$
68 Botezelli JD, Cambri LT, Ghezzi AC, Dalia RA, PP MS, Ribeiro C, Voltarelli FA, Mello MA. Different exercise protocols improve metabolic syndrome markers, tissue triglycerides content and antioxidant status in rats. Diabetol Metab Syndr 2011; 3: 35 [PMID: 22182600 PMCID: PMC3296599 DOI: 10.1186/1758-5996-3-35]

69 Carani C, Isidori AM, Granata A, Carosa E, Maggi M, Lenzi A, Jannini EA. Multicenter study on the prevalence of sexual symptoms in male hypo- and hyperthyroid patients. J Clin Endocrinol Metab 2005; 90(12): 6472-6479 [PMID: 16204360 DOI: 10.1210/jc.2005-1135] 